\title{
The Pattern and Outcome of Civilian Vascular Injury in a Teaching Hospital over a 7-Year Period
}

\author{
I. A. Nwafor ${ }^{1}$, J. C. Eze', N. Ezemba1, F. A. Onyekwulu², C. I. Ngene', J. M. Chinawa ${ }^{3,4}$ \\ ${ }^{1}$ Department of Surgery, University of Nigeria Teaching Hospital, Enugu, Nigeria \\ ${ }^{2}$ Department of Anaesthesia, University of Nigeria Teaching Hospital, Enugu, Nigeria \\ ${ }^{3}$ Department of Paediatric, University of Nigeria Teaching Hospital, Enugu, Nigeria \\ ${ }^{4}$ Department of Pediatrics, College of Medicine, University of Nigeria, Enugu Campus, Enugu, Nigeria \\ Email: "Igbochinanya2@yahoo.com
}

Received 18 December 2015; accepted 14 February 2016; published 17 February 2016

Copyright (C) 2016 by authors and Scientific Research Publishing Inc.

This work is licensed under the Creative Commons Attribution International License (CC BY).

http://creativecommons.org/licenses/by/4.0/

(c) (i) Open Access

\begin{abstract}
Background: The exact incidence of vascular injuries in Nigeria as a country especially south-east zone of Nigeria is unknown on account of under reporting and uncoordinated management of victims. Aim: To determine the pattern and outcome of common civilian vascular injuries managed in a teaching hospital in the south-east zone of Nigeria. Method: This is a retrospective study from January, 2007 to December, 2013. All case records of common civilian vascular injuries presenting at the accident center and those referred to the clinics as well as operation register and data banks of managing surgeons, were retrieved and analysed. Results: The age range of 12 - 75 years was recorded for the 26 patients. In this spectrum, age range of 21 - 30 years $(19.2 \%)$ was the highest while the age range, 61 - 70 years $(0 \%)$ was the lowest. One female $(3.9 \%)$ and twenty five males $(96.1 \%)$ were recorded, giving a female to male ratio of 1:25. In the upper extremity, brachial artery $6(23.1 \%)$ was the most involved vessel while in the lower extremity, the most involved was the femoral artery $9(34.6 \%)$. The patterns of presentation were isolated bleeding $10(38 \%)$, arterivenous fistula $1(3.5 \%)$ and pseudoaneurysm $8(30 \%) .23(88 \%)$ had good outcome. Conclusion: The incidence is about 4 cases per year. $23(88 \%)$ had good outcome. The shortcoming of lattending physicians was because they were not conversant with hard and soft signs of vascular injuries with attendant limb loss and death of one of the victims. This short coming can be averted by training and retraining of doctors.
\end{abstract}

\section{Keywords}

Vascular System Injury, Vascular Surgical Procedures, South-East Nigeria, Pattern and Outcome

"Corresponding author.

How to cite this paper: Nwafor, I.A., Eze, J.C., Ezemba, N., Onyekwulu, F.A., Ngene, C.I. and Chinawa, J.M. (2016) The Pattern and Outcome of Civilian Vascular Injury in a Teaching Hospital over a 7-Year Period. World Journal of Cardiovascular Diseases, 6, 44-53. http://dx.doi.org/10.4236/wjcd.2016.62006 


\section{Introduction}

Nigeria is presently divided into six geo-political zones: southeast, south-south, southwest, north-central, northwest and northeast [1]. The incidence of common civilian vascular injuries due to trauma in this country and West African sub-region is unknown due to under reporting unlike south Africa and United States of America [2] [3]. The incidence in the southwest particularly, Lagos state has been reported recently [4]. The study of vascular injuries in the eastern Nigeria, comprising the southeast and southsouth geopolitical zones is more than 3 decades [5], and judging from monumental increase in civilian and armed conflicts in the modern era, the incidence reported by this previous study cannot be truly relied upon now. Locations considered as high risk include travelling at high speed on Nigerian roads, living in areas where there is boundary or chieftaincy dispute, being with members of cult gang or carrying cash and other valuables without police escort. Extremity and cervicothoracic vascular injuries occur both in isolation and in combination with other injuries especially orthopaedic injuries of the extremities [6]. Between the first study [5] and now, there has been proliferation in the number of high speed and articulated vehicles, which with the attendant poor road infrastructure, and careless or reckless drivers, have resulted in increase in traumatic vascular injuries from motor vehicle crashes [7]. Kidnapping, university campus cult activities, terrorist activities, political violence, armed robbery and conflict over traditional titles are the modern era civilian conflicts which never featured prominently, three decades ago [8]. Arms are used extensively in all these listed events.

Peripheral vascular injuries constitute $4 \%$ - 6\% of major trauma [9]. This type of injury leads to emergency situation because of acute blood loss and impending fatal outcome if severe and no intervention is instituted urgently.

Although uncommon, the complications of haemorrhage and ischemia can be life threatening and lead to limb loss. Prompt diagnosis and appropriate treatment cannot be overemphasised, as delay allows irreversible ischemic injury to take place. Tourniquet encourages propagation of intravascular thrombosis, which results in eventual loss of function or even limb itself [10]. The mechanism of injury can be direct or indirect. The former variety includes blunt trauma and penetrating injuries, for example, gunshot and stab wounds. The later are usually due to fractures and dislocations resulting from road traffic accident (RTA) as well as iatrogenic injuries resulting from vascular interventions such as central venous lines placements and angiography procedures. The penetrating injuries to arteries are the major causes of mortality and morbidity in the injured patients. However, the results are more promising in penetrating injuries relative to blunt types [11]. It is a known fact that serious vascular injury is low in low-energy wounds.

Diagnosis can be challenging. However, using hard (pulsatile bleeding, audible bruit, palpable thrill, expanding or pulsatile haematoma and signs arterial insufficiency evidenced by 6 Ps) and soft signs (palpable but diminished pulse, isolated peripheral nerve injury, large non-pulsatile haematoma, prolonged capillary refill and ankle-brachial index of $<0$ - 9) criteria alongside requisite investigations where appropriate, is usually adequate. This is because hard signs have more than $90 \%$ positivity of arterial injury while soft signs have about $35 \%$ positivity of arterial injury.

When repair is indicated, operative procedures may be in the form of the followings: direct repair, venous or prosthetic patch repair, end-to-end anastomosis, interposition of autogenous vein or prosthetic graft. In the standard set up, for example, level 1 trauma centre, patient has to reach the hospital within 6 to 12 hours to obtain favourable outcome. In this case, the shortened transport time, adequate resuscitation, repair of the damaged vessels, and availability of expert surgeons do contribute to the successful outcome [12]. Associated extensive soft tissue injury, bony injury or avulsed nerve may make limb useless even in the setting of a successful repair. Therefore the liberal use of fasciotomy in the injured extremity is imperative in reducing postoperative oedema and compartment syndrome. A good knowledge of 6 Ps which comprise of pain, pulsenessless, paraesthesiae, paralysis, pallor and poikilothermia or perishing cold with successful management of traumatic vascular injury, aggressive resuscitation and prompt surgery [13] will preserve life and prevent limb loss.

In accident and emergency centers, no special investigation is worldwide standard, nonetheless, selective use of angiography may be useful. Urgent amputation is indicated when reperfusion cannot be restored and the limb is severely injured without prospects of function [14].

\section{Patients and Methods}

From January, 2007 to December, 2013, a period of 7-year, when the University of Nigeria Teaching Hospital 
moved from its temporary site in Enugu to the permanent site at Ituku-Ozalla, about 26 cases of common civilian vascular injuries of neck, upper and lower extremities, were managed in our centre. At the end of that period, certain data from such patients were retrieved and analysed. The analytical method was by simple arithmetic percentage. These patients' demographics such as age and sex and involved vessels, pattern of presentations and referrals as well as other data which included aetiological factors, treatment offered and outcome of such treatment were analysed by simple statistics. Those with crushed injuries to the extremities otherwise known as mangled extremity injuries were excluded from the study as it was difficult to determine the vessel (s) affected.

Those patients that presented at the accident center in shock state, especially in association with non-vascular injures were resuscitated according to acronym ABCDE ladder and Advanced Trauma Life Support-((ATLS) Protocol. For the definitive management of the injured vessels, the following principles were followed. From Table 1, those that were bleeding had laceration and were received within 6 - 12 hours of injury. Those with gangrene, pseudoaneurysm or arteriovenous fistula came within (2 days to 4 years) after the initial injury.

Table 1. Showing the pattern and outcome of vascular injuries in UNTH, Enugu from 2007-2013.

\begin{tabular}{|c|c|c|c|c|c|c|}
\hline SN & Patient ID & Age & Sex & Type of vessel & Pattern of presentation & Outcome \\
\hline 1 & NA & 30 & M & RA & Bleeding & SR \\
\hline 2 & OC & 19 & M & FA & Bleeding, shock & Amputation \\
\hline 3 & UC & 24 & M & $\mathrm{BA}$ & Bleeding & SR \\
\hline 4 & OCC & 28 & M & $\mathrm{BA}$ & PseudoAn & SR \\
\hline 5 & MA & 57 & M & FA & Bleeding, limb gang & Amputation \\
\hline 6 & OS & 34 & M & $\mathrm{BA}$ & Bleeding, 6Ps & SR \\
\hline 7 & AJ & 42 & M & PA & Bleeding & SR \\
\hline 8 & NC & 22 & M & ECA & Bleeding, shock & SR \\
\hline 9 & MA & 75 & M & Prof A & PseudoAn & SR \\
\hline 10 & UU & 35 & M & $\mathrm{BA}$ & Bleeding & SR \\
\hline 11 & OT & 12 & M & RA & Bleeding & SR \\
\hline 12 & OC & 51 & $\mathrm{PA}$ & $\mathrm{PA}$ & Bleeding & SR \\
\hline 13 & $\mathrm{OE}$ & 45 & M & FA & PseudoAn & SR \\
\hline 14 & MR & 48 & M & $\mathrm{BA}$ & Bleeding, 6Ps & SR \\
\hline 15 & IS & 34 & M & FA & PseudoAn & SR \\
\hline 16 & CK & 18 & M & FA & Bleeding, shock & SR \\
\hline 17 & AN & 23 & M & CCA & Bleeding, shock & SR \\
\hline 18 & EC & 26 & M & PA & Bleeding, \#bones & SR \\
\hline 19 & NC & 28 & M & FA & PseudoAn & SR \\
\hline 20 & $\mathrm{KN}$ & 23 & M & $\mathrm{BA}$ & AVF, local gigantism & SR \\
\hline 21 & OJ & 29 & M & FA & PseudoAn & SR \\
\hline 22 & ND & 22 & M & EJV & Bleeding, Neck swelling & SR \\
\hline 23 & MY & 20 & M & AxA & PseudoAn & SR \\
\hline 24 & EO & 21 & M & DorA & Bleeding & SR \\
\hline 25 & ES & 17 & $\mathrm{~F}$ & RA & PseudoAn & SR \\
\hline 26 & AS & 40 & M & CFA & Whole limb gan & Death \\
\hline
\end{tabular}


Exploration of site of injury is preceded by achieving proximal and distal control of the bleeding vessel. Before clamping the vessels with appropriate vascular clamps, systemic heparinization was achieved through intravenous route in order to increase the clotting time and thereby prevent thrombosis during the procedure. However, where there were associated injuries, regional injection of heparin was used. Vascular sutures such as Prolene ${ }^{\mathrm{TM}}$ 4-0, 5-0 or 6-0 with small needles were used to repair the vessels. These sutures including normal saline (0.9\%) were procured from our hospital pharmacy as part of patient's requirements for surgical operation. Surgical loupe was used to aid the visibility of these tiny sutures and placement of needle during suturing as it was difficult to determine the vessel (s) specifically affected.

On occasions, when there was need for end to end anastomosis of the vessels because of limited injury, mobilisation of the affected vessel will help to reduce tension on suture lines. Two or three stay sutures were put in such a way as to hold the disrupted ends in position as well as serve as guides to the placement of the repair sutures; see Table 2 for the categories of vascular procedures as per the nature of the injury.

Any defect was bridged with greater saphenous vein or synthetic graft such as Dacron ${ }^{\mathrm{TM}}$ or Gortex ${ }^{\mathrm{TM}}$ graft. Autologous greater saphenous vein had to be harvested through open harvest. The endoscopic method was not used in this study but open method was used for harvesting the vein. The vein used thereafter was prepared in heparinised normal saline $(0.9 \%)$ and used in reversed direction. Synthetic graft was for vessels above the knee. Non stocking of the synthetic grafts by our center was a challenge when the need arose. Appropriate sizes when procured were however used and with subsequent neo-endothelizationin view anticoagulant was not given to patient for life rather anti-platelet aggregator was prescribed. To prevent circulatory failure blood and blood products, plasma expanders and crystalloid were used for those that presented in shock on account of severe blood loss. Anaesthesia was usually general anaesthesia in emergency cases.

\section{Results}

The age range of 12 - 75 years was recorded in the 26 patients as in Table 1. In this spectrum, age range of 21 30 years with 11 patients (19.2\%) was the highest while the age range, $67-70$ years with no patient $(0 \%)$ was the lowest. In the upper extremity, the injured vessels were brachialartery 6 (23.1\%), radialartery $3(11.5 \%)$ and axillary artery $1(3.9 \%)$. In the lower extremity the injured vessels were the femoralartery 9 (34.6\%), poplitealartery 3 (11.5\%), and dorsalis pedisartery 1 (3.9\%). In the neck, common carotid artery 2 (7.7\%), and external jugular vein 1 (3.9\%) were involved.

The time interval between injury and its first evaluation was considered. It is stated those that presented with bleeding came within 6 - 12 hours while those with gangrene, pseudoaneurysm came within (2 days - 4 years) after the initial injury.

The pattern of presentation and referral included bleeding around the sites of vascular injury usually accompanied with tied pieces of clothes or bandages; haemorrhagic shock usually types III or IV; ischemia indicated by 6 Ps (pain, pulselessness, pallor, paralysis, paraesthesia and poikilothermia). Others included traumatic pseudoaneurysm presenting as pulsatile mass or traumatic arteriovenous fistula, AVF presenting in the form of local gigantism with varicosity of veins. See Table 3 for the percentage distribution.

The aetiological factors implicated were motor vehicle crash 12 (46.2\%), gunshot injury, 6 (23.1\%), knife stab (15.4\%), stab from broken bottles 3 (11.5\%) and stab from spokes of umbrella 1 (3.9\%). See Figure 1. The

Table 2. Showing the pattern of presentations of vascular injury.

\begin{tabular}{clcc}
\hline s/n & \multicolumn{1}{c}{ Pattern of presentation } & Total number & Percentage (\%) \\
1 & Bleeding tied with cloth/bandaged & 10 & 38 \\
2 & Bleeding in shock state & 2 & 2 \\
3 & Bleeding with 6 Ps & 3 & 15 \\
4 & Obvious limb gangrene & 3.8 \\
5 & Arteriovenous fistula with local gigantism and varicose veins. & 8 \\
6 & Pseudoaneurysm & 30 \\
\hline
\end{tabular}


Table 3. Age distribution of patients.

\begin{tabular}{ccc}
\hline Age range (years) & No. of vessels involved & Percentages (\%) \\
\hline $10-20$ & 5 & 19.2 \\
$21-30$ & 11 & 42.3 \\
$31-40$ & 3 & 11.5 \\
$41-50$ & 4 & 15.4 \\
$51-60$ & 2 & 7.7 \\
$61-70$ & 0 & 0 \\
$71-80$ & 1 & 3.9 \\
Total & 26 & 100 \\
\hline
\end{tabular}

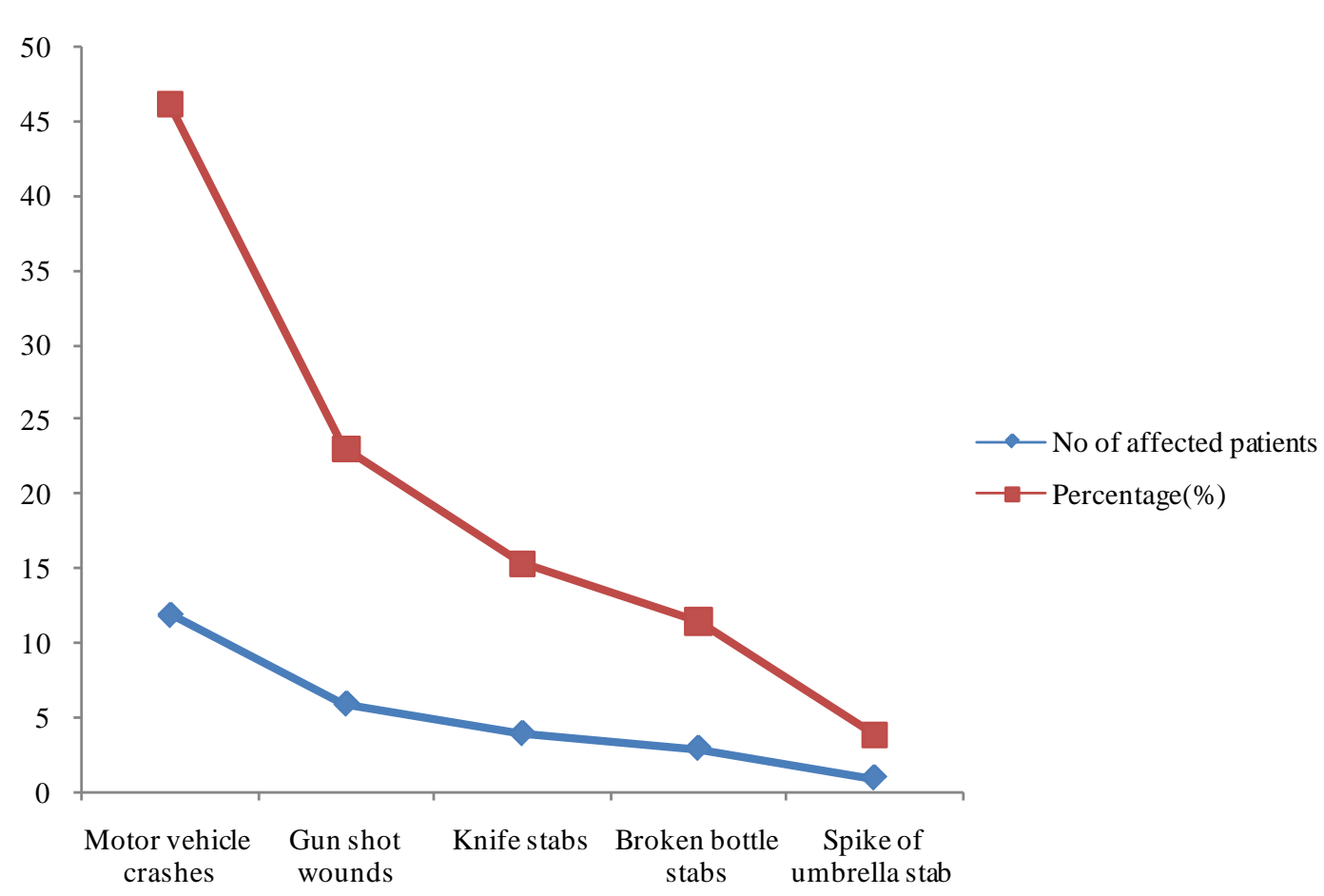

Figure 1. Showing the aetiological factors. Keys: RA, radial artery, FA, femoral artery, BA, brachial artery, PA, Popliteal artery, ECA, external carotid artery, Prof A, profundus femoral artery, CCa, common carotid artery, EJV, external jugularvein, Ax A, axillary artery, Dor A, dorsalis pedis artery, CFA, common femoral artery, SR, successful reconstruction.

deciding factor for surgical intervention are highlighted in Table 2, otherwise called indications for surgery. Table 1 and Table 4 show outcome. 23 (88\%) patients had successful outcome because there was restoration to normal status.

The treatment offered ranged from direct suture repair, autologous vein patch repair, a segment of autologous greater saphenous vein interposition and ligation. Others were repair of traumatic pseudoaneurysm and arteriovenous fistula. In the outcome of these patients, 1 patient (3.9\%), with crush injury to the left femur, with multiple femoral bone fracture and extensive laceration of the left femoral artery died due to late presentation and refusal to accept unilateral limb disarticulation. See Table 2. Two patients (7.7\%) had below knee amputation, 1 patient (3.9\%) had acute renal failure. All complicated cases were due to late presentation. Others had outcome that ranged from excellent to good; see Table 4. Postoperative physiotherapy played tremendous role in those that had successful outcome. 
Table 4. Showing the outcome of vascular injuries managed over a 7-year period.

\begin{tabular}{ccccc}
\hline SN & Outcome & No. & Percentage(\%) & Remark \\
\hline 1 & Successful reconstructinon & 23 & 88 & \\
2 & Amputaiopn/limb loss & 2 & 8 & Co-managed with Orthopaedic team \\
3 & Death & 1 & 4 & Refused amputation \\
Total & & $\mathbf{2 6}$ & $\mathbf{1 0 0}$ & \\
\hline
\end{tabular}

\section{Discussion}

In Lagos state, south-west zone of Nigeria, Thomas MO et al., 2005 [4] demonstrated that vascular injuries are commoner in males than females. In that study, penetrating injuries accounted for $78.1 \%$ while blunt injuries produced $21.9 \%$. The age range in the same study showed that highest number of vascular injury was 30 - 39 years. Moreover, femoral artery followed by brachial artery represented the greatest geographical area of vascular injury respectively. Our own study was in agreement with the above in terms of sex predilection, geography of the injury but differed in age range of highest occurrence. We showed that $96.1 \%$ of males were affected and that $34 \%$ and $23 \%$ of femoral and brachial arteries respectively were involved. The commonest cause of vascular injury was penetrating injury and the age range of 21 - 30 years represented $42.1 \%$ in our study. Management wise, there was no significant difference.

In another study in Kwara State in North central zone of Nigeria, Adeoye et al., 2011 [15] showed male preponderance (71.4\%). Highest occurrence of vascular injury was in the age range of 20 - 39 years $(35.7 \%)$ and blunt trauma represented the most common aetiological factor. Age range with highest injury was in tandem with our study. Penetrating injury was the common aetiological factor. Direct suturing (64\%) was the main method of treatment in his study unlike ours where revised saphenous vein graft (23\%) dominated. There has been no documented study from north-west, north-east and south-south zones of Nigeria.

In Ghana, Nigeria’s West African neighbour, a study by Aduful and Hodasi in 2005 [11], penetrating trauma accounted for $82.7 \%$ of the 52 patients studied, while blunt trauma accounted for $11.5 \%$. Brachial artery injury was the commonest injured vessel. These findings agrees with ours aetiologically but is at variance with our study in terms of geography of the injury. Femoral artery was the most injured vessel. Vascular reconstruction was successful in $84.6 \%$ while amputation was offered in $7.7 \%$ in Aduful et al. report. In our study, vascular reconstruction was successful in $88 \%$ while $8 \%$ had amputation.

In USA, a multicenter study of vascular injury by David VF et al. in 2011, [16] showed that penetrating vascular injury accounted for $75 \%-80 \%$ while blunt injury accounted for $5 \%-25 \%$. This is definitely in agreement with our study because penetrating trauma accounted for $53.8 \%$ while blunt trauma was $46.2 \%$. See Figure 1.

Morbidity and mortality emanating from vascular trauma is enormous. It has the highest resuscitation priority after airway and breathing in the acronym of ABCDE resuscitation ladder [7]. The most important and critical prognostic factors are the duration of warm ischemic time, level and type of vascular injury, collateral circulation around the level of the injury, tissue damage or crush injury and patient factors such as co-morbid medical conditions, for example diabetes mellitus, obesity and extremes of life.

Whenever there is peripheral and cervico-thoracic vascular injury, the affected anatomical part of the body will manifest the listed features if a vascular supply is compromised. Such features are loss of tissue viability, ischaemic pain, paraesthesia, pulselessness and paralysis, pallor, paralysis and perishing cold or poikilothermia. This is seen in the involvement of brachial or femoral artery with affectation of the body parts they supply. On the other hand, the forearm has ulnar and radial arteries, while the leg has posterior, anterior tibial and fibular arteries [17]. If there is functional collateral supply as seen in the forearm and leg one of the arterial supplies could be lacerated without compromise of blood supply to the distal hand or foot of the ipsilateral side. In this scenario, if bleeding is controlled by ligation of the proximal and distal bleeding ends of the affected vessel, it will serve as definitive treatment for the vascular injury [18]. However, there may be the need to restore the blood volume and haemoglobin level to normal functional status.

In situations where there must be re-establishment of vascular continuity in the face of injury, operative procedure is time bound. This is where the application of knowledge of ischaemic time is necessary. The ischaemic 
time is subdivided into warm and cold time with the latter being of longer duration. Cold ischaemic time is achieved by cooling the deprived part of the body with cooling blanket connected to hemotherm machine in order to produce both local and regional hypothermia. There could also be isolated perfusion of cold fluid. In this way, ischaemic time is prolonged with subsequent good outcome post revascularisation. This prevents reperfusion injury.

As has been stated, aim of the study is first to determine the pattern and mechanism of vascular injuries managed in our zone. Secondly, to review the mechanisms of injury or the aetiological factors and thirdly, to study the relationship between latent period for revascularisation and the outcome of treatment such as surgical intervention.

The age range most prone to vascular injury as observed in our study was between 21 - 30 years (42.3\%). Similar study have been reported by Hood et al., in their study of age range of 25 - 40 years (65\%) [19]. Kudson et al., reported on the 42 patients and showed that most commonly affected group was between 20 - 40 years (60\%) [20]. Large number of cases in this age group can be explained by the fact that persons in this age group are at the peak of their activity and are subject to the hazards of accidents and injuries. In our study we observed that males (96.1\%) are more vulnerable than females (3.9\%) to sustain peripheral and cervical vascular injuries. Motor vehicle accident is the most frequent aetiology of peripheral vascular injury in our study. This is quite unlike Fryberg et al. that studied 65 victims of peripheral vascular injuries caused by firearms in one year period representing 58\% of vascular trauma [21], just like Thomas MO et al., who studied 41 victims of common civilian vascular injuries in Lagos metropolis of Nigeria and found that 23 (56.1\%) were due to civilian gunshot wounds [15].

In our study, brachial artery was commonly affected in the upper extremity (23.1\%) and femoral artery in the lower extremity (34.6\%). see Figure 2. These observations are similar to the study of Nassoura et al., who described a study of 101 patients in whom femoral artery injury of $40 \%$ was most common [22]. Common pattern of vascular injury that was found in our study was laceration of vessel wall as top pathology with or without thrombosis. This was followed by loss of vessel wall segment, complete transection and partial transection. Savage and Waker observed in their study of vascular injuries a number of 40 (60\%) patients that had lacerations of vessel wall and 10 (15\%) had loss of vessel wall segment [23].

Methods of vascular repair adopted in our study were end-to-end anastomosis 5 (19\%), interposition of reversed vein graft 6 (23\%) direct suture of laceration 2 (8\%) and ligation 3 (12\%) (Table 5). According to stratification of vascular injuries management into prehospital (direct pressure to the sites, ABC management, fluid and/or blood for shock, avoidance of proximal tourniquet unless as last resort) emergency (intravenous fluid in non-injured limb, Foley catheter to the vessel, avoidance of blind clamping of vessels) and definitive treatment,

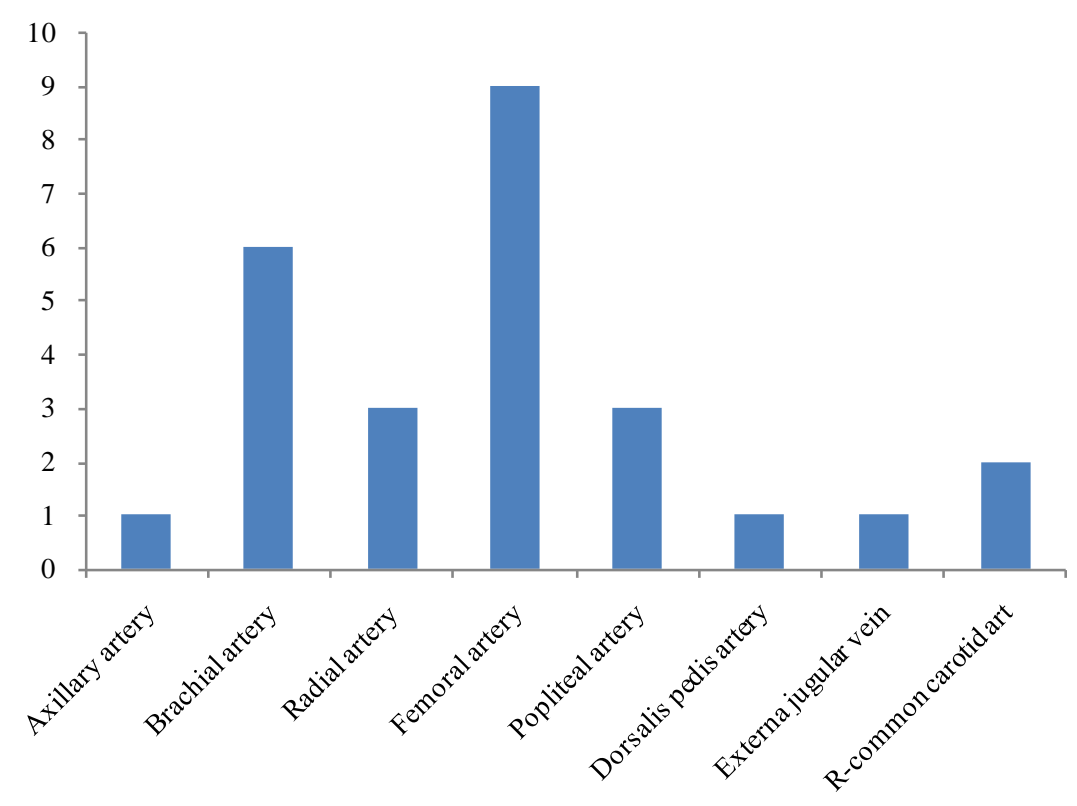

Figure 2. Showing the pattern of vessels involved in the injury. 
Table 5. Showing the various management methods of vascular injury.

\begin{tabular}{cccc}
\hline $\mathbf{s} / \mathbf{n}$ & Management methods & Total number & Percentage (\%) \\
\hline $\mathbf{1}$ & Direct suturing & 2 & 8 \\
2 & Ligation including areas of pseudoaneurysm & 9 & 35 \\
3 & End to end anastomosis & 5 & 19 \\
4 & Revised great saphenous vein graft & 4 & 15 \\
5 & Prosthesis graft & 3 & 12 \\
6 & Amputation & 2 & 8 \\
7 & Died for refusing intervention & 1 & $\mathbf{1 0 0}$ \\
\hline
\end{tabular}

ours were both emergency and definitive management as vascular surgeons. Hugh reported on his study of primary repair of wounds of major arterial trauma, and that end-to-end anastomosis was the common method [24]. Vanway described that interposition of reverse vein graft is usually needed in cases where vascular injury is associated with blunt trauma [25]. This center does open and reverse direction vein grafting. Where there is a valvotome to do valvotomy, the harvested greater saphenous vein undergoes valvotomy and is subsequently used in its normal anatomical direction. Some centers use the vein in this way [26]. Valvotome was not used in this study. Vein harvest can be done endoscopically or via open procedure. Our center does open harvesting of the veins for grafting.

Pseudoaneurysm, which was formerly called false aneurysm, was observed as a complication of the vascular injury occurred in 2 (8\%) of our patients. Pulsatile swelling with scar was the common pattern of presentation. All were repaired, using vascular sutures after obtaining proximal and distal control and subsequent exposure of the laceration. The swelling was usually formed by blood clot and adjacent anatomical structures. Skin incision and careful evacuation of clot exposed the puncture site.

The overall management of the patient involved taking care of any observed deficiency. Blood transfusion was done using whole blood to replace loss and aim was to achieve haemoglobin level of $10 \mathrm{~g} / \mathrm{dl}$ and above. Antibiotics were used presumptively and therapeutically to achieve good outpatient outcome. It is known that if there was breach in integrity of the aseptic state of the vascular system, there was the possibility of bacteremia and possible septic shock. Wounds were closed primarily after vascular repair with non-absorbable nylon, size 2-0 in adults and removed between 5 and 14 days depending on the part of the body involved. Associated bone involvement was managed conjointly with orthopaedic unit who usually fixed the fractures.

Road traffic accident accounted for the highest number of victims of vascular injury in this study. This underscores the need for managers of road safety to do more in reducing the incidence of vascular injury. It is a known fact that prevention of any lesion is better than treatment. The road managers are agents of government and the state of road infrastructure and state of vehicles bear have direct bearing on the posture of government. Therefore government should exhibit the necessary political will in tackling this menace.

Gunshot injury was second cause of vascular injury. The patients were those that survived death from exsanguinations. Armed robbery victims formed the bulk in this group. Management ranged from resuscitation to exploration, vascular repair and rehabilitation. The use of guns by criminals poses great danger to the populace and government should rise to the challenge.

The arteriovenous fistula was noted in our study and constituted about 3 (15\%). See Table 3 . This presented with local gigantism and varicosity of the tributary veins. Management consisted obtaining proximal and distal control of the arterial segment, arteriotomy and direct suturing of the communicating site (s). Quadruple ligation is an option when the involved artery and veins have adequate collaterals. This was not however adopted in our study.

Residual oedema was encountered as a postoperative complication. It was treated conservatively by [pelevation and compression bandaging. It was due to combined effect of surgery and trauma. Rate of amputation in our study was 4 (15\%) when revascularisation was established after 12 hours, but never occurred when revascularisation was established between 6 - 12 hours. Fryberg et al., noted that gangrene was rare in repair done within 6 
hours but occurred in 50\% of cases when repair was delayed for more than 12 hours [21]. This leads to overshooting of warm ischaemic time with resultant failure of limb salvage and leads to limb loss through amputation or subsequent death from reperfusion syndrome as well as late complications that warrant the use of sophisticated investigative tools. These bad prognostic factors can be avoided if there is early recognition and prompt referral to vascular surgeons for adequate treatment. Follow up plan is in place via clinic visits and clinical assessment. If there is indication, further assessment is done with Doppler ultrasonography and possibly angiography.

\section{Conclusions}

The common civilian vascular injuries in our study, affect the upper and lower extremities including the neck vessels in varying degrees, ranging from mild, moderate, severe/critical. It occurred in all sexes and all age groups especially the youths. The outcome ranged from good, fair and bad. It depended on the type and mechanism of injury, time of presentation, collateral supply at the level of injury, co-morbidity of the victims and the role of the primary physician.

Primary physicians should have high index of suspicion of vascular injury and be able to refer promptly. All cases of peripheral vascular injuries associated with hard signs should be surgically explored and every effort should be made to achieve revascularisation within 6 - 12 hours.

\section{Acknowledgements}

I personally acknowledge our departmental secretarial staff and the Head of surgery for their wonderful role in production of this article.

\section{Congress}

This article was presented at $43^{\text {rd }}$ Annual General meeting and Scientific Conference of Nigeria Cardiac Society, held at Uyo, Akwa Ibom state, Nigeria, September, 2014.

\section{Funding}

The funding of this work was borne by the contributions of the authors from their salaries.

\section{Conflict of Interest}

There is no conflict of interest whatsoever.

\section{References}

[1] Odiegwu, M., Ubakoh, O., Baiyewu, L. and Okepi, A. (2012) Constitution: Six Geopolitical Zones Divide the North and the South. Punch Newspaper.

[2] Degiannis, E., Velhamos, G., Krawaczykowoki, D., Levy, R.D., Souter, I. and Saada, R. (1994) Penetrating Injuries of the Subclavian Vessels. British Journal of Surgery, 81, 524-526. http://dx.doi.org/10.1002/bjs.1800810412

[3] Degiannis, E., Levy, R.D., Velhamos, G.C., Potokar, T. and Saada, R. (1955) Penetrating Injuries of the Femoral Artery. British Journal of Surgery, 82, 492-495. http://dx.doi.org/10.1002/bjs.1800820420

[4] Thomas, M.O., Giwa, T.O. and Adekoya-Cole (2005) Arterial Injuries in Civilian Practice in Lagos, Nigeria. Nigerian Journal of Clinical Practice, 8, 65-68.

[5] Anyanwu, C.H., Umeh, B.U. and Swarup, A.S. (1982) Experience with Civilian Vascular Injuries in Eastern Nigeria. Angiology, 33, 90-97. http://dx.doi.org/10.1177/000331978203300203

[6] Horn, J.K. (2000) Is Angiography Mandatory for Zone 1 Injury of the Neck? Journal of Trauma, 48, 208-213. http://dx.doi.org/10.1097/00005373-200002000-00002

[7] Ranna, S.H., Farani, T.M., Jamal, Y. and Afzal, M. (2008) Peripheral Vascular Injuries, Epidemiology and Management. Professional Medical Journal, 15, 54-60.

[8] Ojo, E., Ibrahim, A. and Obiano, S. (2007) Gun Shot Injuries in a North Eastern Nigeria Tertiary Hospital. The Internet Journal of Surgery, 16, 12.

[9] Fanibar, G., Roy, S.A., Wall, M.J. and Mattox, K.L. (1995) Predictors of Amputation for Popliteal Artery Injuries. 
Journal of Surgery, 170, 568-571. http://dx.doi.org/10.1016/S0002-9610(99)80017-8

[10] Debakey, M.E. and Simeon, F.A. (1949) Battle of Arteries in World War II. Annals of Surgery, 123, 534-579. http://dx.doi.org/10.1097/00000658-194604000-00005

[11] Aduful, H.K. and Hodasi, W.M. (2007) Peripherla Vascular Injuries in Accra. Ghana Medical Journal, 41, $186-189$.

[12] Hey, R. and Hoyt, D.B. (1995) Vascular Trauma. In: Cusheri, A., Giles, G.R. and Mossa, A.R., Eds., Essential Surgical Practice, 3rd Edition, Butterworth-Heinemann, Oxford, 545-547.

[13] Degiannis, E., Velmahos, G.C., Levy, R.D., Wouter, S., Badical, T.V. and Saada, R. (1996) Penetrating Injuries of Iliac Arteries: A South African Experience. Surgery, 119, 146-150. http://dx.doi.org/10.1016/s0039-6060(96)80162-0

[14] Winkinson, M.G., Birch, R. and Bonney, G. (1993) Brachial Plexus Injury, When to Amputate? Annals of Surgery, 24, 603-605.

[15] Adeoye, P.O., Adebola, S.O., Adesiyin, O.A.M. and Braimoh, K.Y. (2011) Peripheral Vascular Procedures in Illorin, Nigeria: Indications and Outcome. African Health Sciences, 11, 433-437.

[16] David, V.F., Frederick, A.M., Ernest, E.M., et al. (2011) Evaluation and Management of Vascular Injury. Part 1, Western Trauma Association/Critical Decision in Trauma. The Journal of Trauma, 70, 1551-1556.

[17] Romanes, G.J. (1986) Cunningham’s Manual of Practical Anatomy, Vol. 1: Upper and Lower Limbs. 15th Edition, Oxford Medical Publications, Oxford.

[18] Clouse, W.D., Rasmussen, T.E., Peristein, D., et al. (2006) Upper Extremity Vascular Injury: A Current In-Theatre War-Time Report from Operation Iraqi Freedom. Annals of Vascular Surgery, 20, 429-434.

[19] Hood, D.B., Weaver, F.A. and Yelhin, A.E. (1998) Changing Perspectives in the Diagnosis of Peripheral Vascular Trauma. Journal of Vascular Nursing, 11, 255-260.

[20] Knudson, M.M., Lewis, F.R. and Atkinson, K. (1993) The Role of Duplex Ultrasonography Arterial Imaging in Patients with Penetrating Extremity Trauma. Archives of Surgery, 128, 103-107. http://dx.doi.org/10.1001/archsurg.1993.01420210097013

[21] Fryberg, E.R., Vines, F.S. and Alexander, R.H. (1990) The Natural History of Clinically Occult Arterial Injuries, a Prospective Evaluation. Journal of Trauma, 29, 577-583. http://dx.doi.org/10.1097/00005373-198905000-00006

[22] Nassoura, Z.E., Ivatury, R. and Simon, R.J. (1996) A Reassessment of Doppler Pressure Indices in the Detection of Arterial Lesions in Proximity Penetrating Injuries of Extremities, a Prospective Study. The American Journal of Emergency Medicine, 14, 151-156. http://dx.doi.org/10.1016/s0735-6757(96)90122-9

[23] Savage, H.S. and Walker, E. (1995) Vascular Trauma on the Rise. Journal of Vascular Nursing, 11, 106-111. http://dx.doi.org/10.1016/s1062-0303(05)80002-0

[24] Hughes, C.W. (1955) The Primary Repair of Wounds of Major Arteries: Analysis of Experience in Korea in 1953. Annals of Surgery, 141, 297-303.

[25] Van III, C.W. (1984) Vascular Suture Techniques. In: Moore, E.E. and Eiswemann, B.E., Eds., Critical Decision in Trauma, 3rd Edition, CV Mosby, St Louis, 648-652.

[26] Eze, J.C. (2014) Distribution of Grafts in Aortocoronary Bypass Surgery. Cardiovascular Surgery Fellowship Experience. The Internet Journal of Thoracic and Cardiovascular Surgery, 17. 